\title{
Comparison of Conductivities of Bulk and Nanowire Morphologies of Electrodeposited Polypyrrole
}

To cite this article: Karen Herdman and Carmel Breslin 2013 Meet. Abstr. MA2013-02 81

View the article online for updates and enhancements.

The ECS is seeking candidates to serve as the

Founding Editor-in-Chief (EIC) of ECS Sensors Plus,

a journal in the process of being launched in 2021

The goal of ECS Sensors Plus, as a one-stop shop journal for sensors, is to advance the fundamental science and understanding of sensors and detection technologies for efficient monitoring and control of industrial processes and the environment, and improving quality of life and human health.

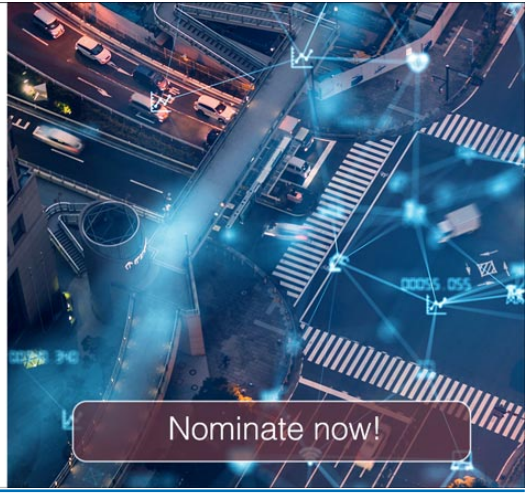




\title{
Comparison of Conductivities of Bulk and Nanowire Morphologies of Electrodeposited Polypyrrole.
}

\author{
Karen Herdman, Carmel B. Breslin
}

Electrochemistry and Materials Chemistry Research Group,

Department of Chemistry, National University of Ireland, Maynooth, County Kildare, Ireland

Conducting polymers have been extensively studied due to their widespread potential applications such as sensors, compact electronic devices and energy storage ${ }^{1}$. Nanostructured materials, like polypyrrole, result in improved analytical characteristics of a polymer ${ }^{2}$. Important factors in the production of nanowire morphology include the $\mathrm{pH}$ at the electrode/electrolyte interface ${ }^{3}$, the concentration of dopant ions and pyrrole, the applied potential and the time of deposition.

Polypyrrole nanowires were electrodeposited on gold electrodes using slightly acidic anions $\left(\mathrm{Na}_{2} \mathrm{HPO}_{4}\right)$ and non-acidic anions $\left(\mathrm{LiClO}_{4}\right)$ at a fixed potential of $0.80 \mathrm{~V}$ vs SCE. The nanowires produced had an average diameter of $89.2 \mathrm{~nm}(\mathrm{n}=50)$. Bulk polypyrrole was electrodeposited using similar conditions but the $\mathrm{pH}$ of the solution system was reduced using concentrated $\mathrm{HCLO}_{4}$. As shown in Figure 1, the SEM micrographs of the bulk and nanowire polypyrrole films are very different.
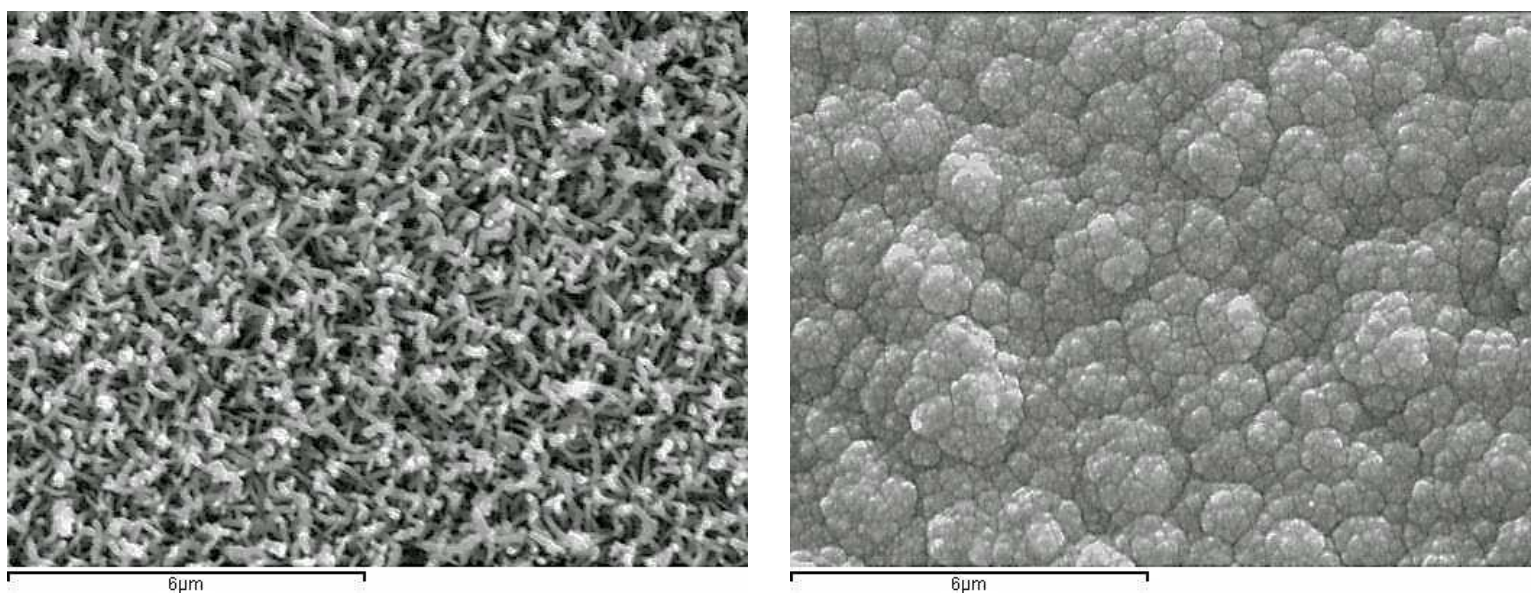

Figure 1: Nanowire and Bulk Morphologies of Polypyrrole

Electrochemical Impedance Spectroscopy experiments were carried out on a bare gold electrode, bulk polypyrrole and polypyrrole nanowires in order to compare their conductivities. The impedance data were analysed using equivalent circuits. Using these results, the conductivities of the systems were calculated. The influence of different electrolytes on the impedance were also studied.

\section{References:}

1. J. Wang, X. Mo, D. Ge, Y. Tian, Z. Wang and S. Wang, Synthetic Metals, 2006, 156, 514-518.

2. F. Ghamouss, A. Brugere, A. Chellachamy Anbalagan, B. Schmaltz, E. Luais, F. Tran-Van, Synthetic Metals, $2013,168,9-15$.

3. C. Debiemme-Chouvy, Electrochemistry Communications, 2009, 11, 298-301. 